\title{
Emergency Surgery for Acute Mitral Valve Obstruction Resulting From Rapidly enlarging Left Atrial Myxoma
}

\author{
M Badrul Alam ${ }^{1}$, SA Quader ${ }^{2}$, AM Asif Rahim ${ }^{1}$, M Sajedul Bari $^{2}$, ZH Khan ${ }^{1}$, Muhammed K hassan ${ }^{2}$ \\ ${ }^{1}$ Department of Cardiac Surgery, NICVD, Dhaka, ${ }^{2}$ Department of Pediatric Cardiac Surgery, \\ NICVD, Dhaka
}

\begin{abstract}
Key words:
Acute Mitral

Left atrial myxomas are benign, slow-growing primary cardiac tumors. They present with gradual onset of one or more of a triad of obstructive, embolic, or constitutional symptoms. Echocardiography aids in the detailed preoperative and intraoperative evaluation of the myxoma for surgical strategy Valve

Obstruction, planning. We describe a case of interstitial hemorrhage in a left atrial myxoma leading to rapid expansion of the tumor with features of acute, mitral valve obstruction. Echocardiography showed Myxoma a cystic area in the left atrial tumor that corresponded to an area of recent hemorrhage confirmed on surgical removal. A 42 yrs old housewife presented with severe dyspnoea, cough and chest pain for 7 days, after detail evaluation she was diagnosed as a case of left atrial myxoma with heart failure. Subsequently she underwent emergency open heart surgery under cardiopulmonary bypass; removal of a huge LA myxoma was done, and recovered uneventfully.
\end{abstract}

Abstract

(Cardiovasc.j. 2016; 8(2): 155-157)

\section{Introduction}

Cardiac myxomas are the most common benign primary tumors of the heart. Although atrial myxomas are the most common primary heart tumors, the association with other cardiac conditions is not frequently reported. In most cases, early diagnosis may prove to be difficult, since the symptoms are often non-specific .The onset of obstructive symptoms depends on the size and mobility of the tumor. We present a case of left atrial myxoma complicated by hemorrhage from rapid enlargement of tumor, which led to rapid development of severe obstructive symptoms. Transesophageal echocardiography showed a tumor mass with a hypoechoic area that was obstructing the mitral valve orifice. Intraoperative and histological examination confirmed a diagnosis of LA myxoma.

\section{Case history}

A 42-year-old, previously healthy, woman was referred to us with a seven day history of sudden onset dyspnea, cough and chest pain. On examination, central venous pressure was elevated and bilateral basal rales were present. No cardiac murmurs were heard. Systemic examination was otherwise unremarkable. Congested lung fields were present on chest roentgenogram. Transthoracic and transesophageal echocardiography showed a mobile, pedunculated mass attached to the interatrial septum in the left atrium, measuring approximately $4 \times 5 \mathrm{~cm}$. A hypoechoic area that resembled a cyst was seen within this mass (Fig 1 ). The mass moved into the mitral orifice during atrial systole, thus partially obstructing it.

The patient underwent emergency surgery for tumor resection. The right ventricle was distended with decreased contractility. The right atrium was not enlarged. Cardiopulmonary bypass with cold blood cardioplegic arrest and topical cooling was instituted. Left Atrial incision was made beginning at the roof of the left atrium. The interatrial septum was incised under guidance of the palpation, left index finger of the surgeon. The tumor pedicle

Address of correspondence: Dr. Badrul alam, Department of Cardiac Surgery, National Institute of Cardiovascular diseases, Dhaka, Bangladesh.Email: alambadrul82@gmail.com 
was attached to the foramen ovale. It was completely excised along with a rim of surrounding atrial septum. The defect thus created was primarily closed. Per operatively test of mitral valve showed good mitral valve function and no other abnormality. The mass showing an area of bluish discoloration. When sectioned, approximately $10 \mathrm{~mL}$ of bloody fluid was found in that area of the tumor (Fig 2).

Postoperatively the patient required diuretic therapy to optimize arterial oxygen saturations. Further postoperative recovery was uneventful. There was no recurrence of the myxoma on follow-up.

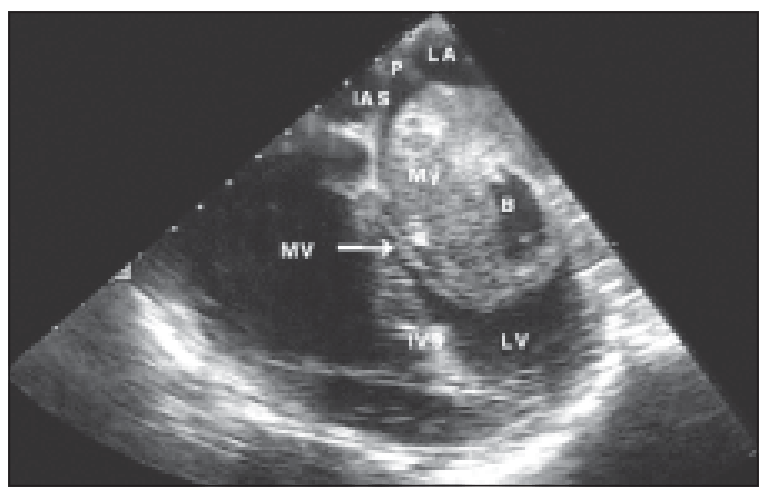

Fig.-1: Transesophageal echocardiogram showing tumor with cystic area attached to the interatrial septum.

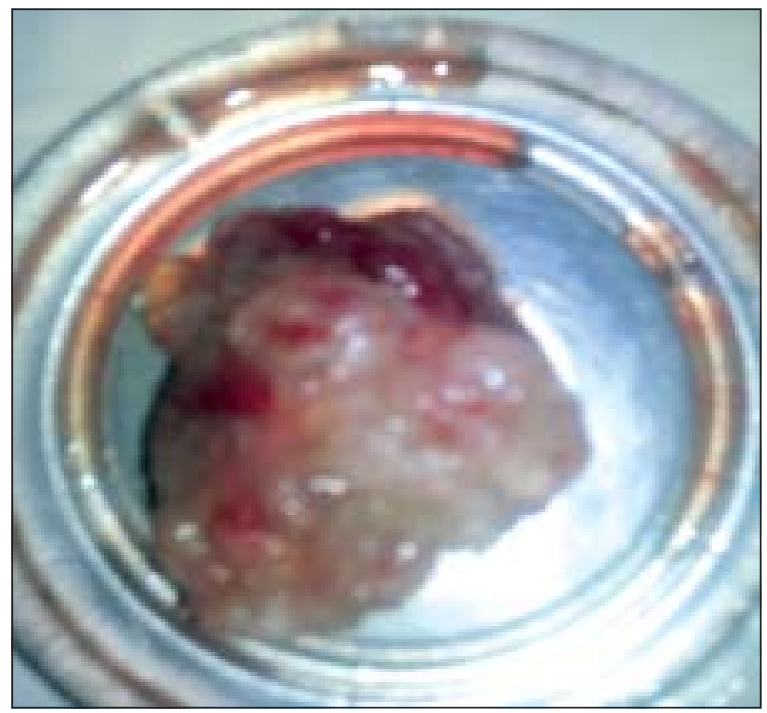

Fig.-2: Pedunculated, smooth-surfaced tumor with areas of hemorrhage.

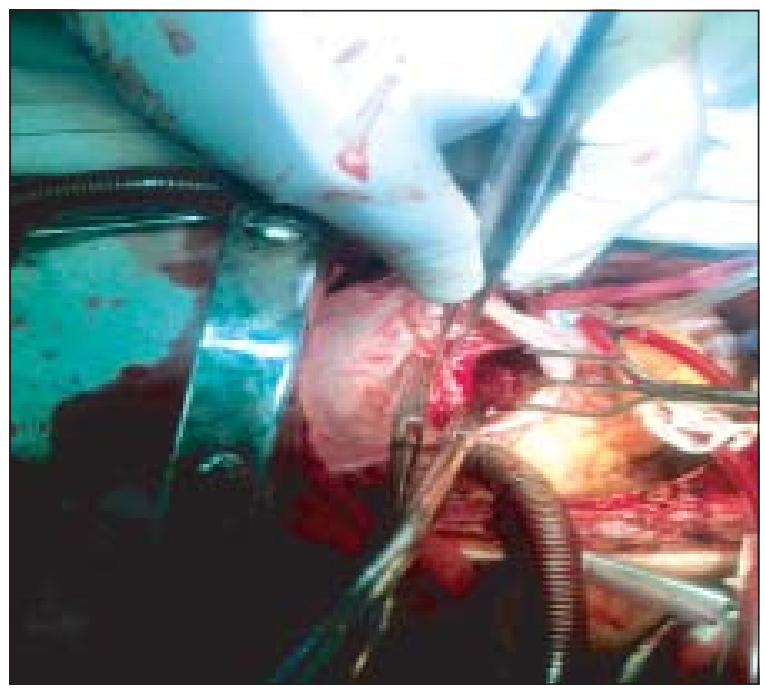

Fig.-3: Peroperative view of LA myxoma by $L A$ tomy.

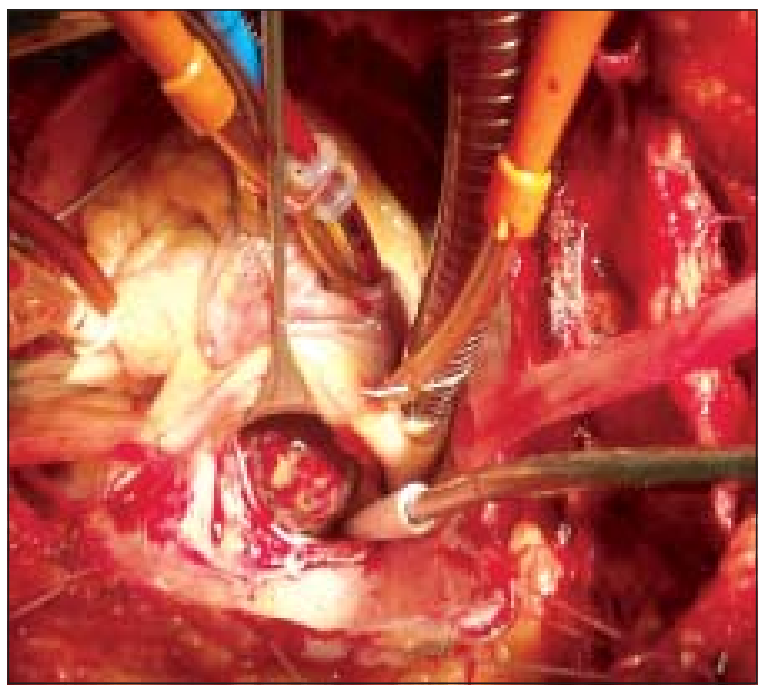

Fig-4: LA Myxoma Before removal.

\section{Discussion:}

Primary tumors of the heart are rare, nearly $75 \%$ of them are benign and almost half of these are myxomas. ${ }^{1}$ Since the availability of twodimensional echocardiography from 1977 onward, the median delay before surgery after development of symptoms was 3 months. ${ }^{2}$ Most patients present with at least one or more symptoms of the classic triad of obstructive cardiac signs, embolic signs, or constitutional and systemic manifestations. Locally the tumor may cause hemodynamic derangement due to either obstruction to flow within the cardiac chambers or the deformation of 
valves. Constitutional symptoms are believed to be secondary to the production of interleukin-1, interleukin-6, and interleukin-8. Distant complications are due to emboli that may occur in any vascular bed, leading to a variety of signs and symptoms. ${ }^{2-4}$ In more than half of the tumors, extensive scarring that replaces myxoid areas, calcification, and metaplastic bone may be present. Hemorrhage and organizing thrombus result in abundant hemosiderin laden macrophages. In 10\% of tumors, elastic tissue and calcification surround the hemosiderin, resulting in gamma bodies. ${ }^{4}$ Multifocal and recurrent diseases are believed to have familial and genetic predisposition. ${ }^{6,7}$ Local recurrence usually occurs due to inadequate surgical resection. Transesophageal echocardiography shows finer details and is considered superior to transthoracic echocardiography in the diagnosis of intracardiac and pericardial tumors. ${ }^{8}$ Postoperative management should include periodic echocardiography for several years, even though recurrence after adequate surgical resection is rare.

\section{Conclusion:}

We report an unusual case of a left atrial myxoma complicated by acute enlargement of the size of the tumor, successfully treated by emergency surgery. This report confirms the value of emergency open heart surgery to remove LA myxoma completely as well as detailed intraoperative evaluation of mitral valve for safety of the patient.

\section{Conflict of Interest - None.}

\section{References:}

1. Reynen K. Cardiac myxomas. New Engl J Med 1995;333: 1610-1617.

2. Pinede L, Duhaut P, Loire R. Clinical presentation of left atrial cardiac myxoma. Medicine 2001;80: 159-172.

3. Revankar SG, Clark RA. Infected cardiac myxoma: case report and literature review. Medicine 1998;77:337344 .

4. Silver MD, Gotlieb AI, Schoen FJ. Cardiovascular pathology, 3rd edition. Philadelphia, PA: Churchill Livingstone; 2001: 591-595.

5. Chow WH, Chow TC, Tai YT, Yip AS, Cheung KL. Angiographic visualization of "tumor vascularity" in atrial myxoma. Eur Heart $J$ 1991; 12:79-82.

6. Shinfeld A, Katsumata T, Westaby S. Recurrent cardiac myxoma: seeding or multifocal disease? Ann Thorac Surg 1998; 66:285-288.

7. Bhan A, Mehrotra R, Choudhary SK, Sharma R, Prabhakar D, Airan B, et al. Surgical experience with intracardiac myxomas: long-term follow-up. Ann Thorac Surg 1998;66:810 -813.

8. Engberding R, Daniel WG, Erbel R, Kasper W, Lestuzzi C, Curtius JM, et al. Diagnosis of heart tumors by transesophageal echocardiography: a multicentre study in 154 patients. Eur Heart J 1993;14:1223-1228. 